\section{SOI: $1.1 /$ TAS DOI: $10.15863 /$ TAS International Scientific Journal Theoretical \& Applied Science}

\author{
p-ISSN: 2308-4944 (print) e-ISSN: 2409-0085 (online) \\ Year: 2017 Issue: $01 \quad$ Volume: 45 \\ Published: $30.01 .2017 \quad \underline{\text { http://T-Science.org }}$
}

I.M. Posokhov

Dr. Sc. (Econ.), Prof

National Technical University "Kharkiv Polytechnic Institute"

posokhov7@gmail.com

U.V. Zhadan

Postgraduate Student

National Technical University "Kharkiv Polytechnic Institute"

SECTION 31. Economic research, finance, innovation, and risk management.

\title{
THE FEATURES OF RISK MANAGEMENT ON OILSEED INDUSTRY ENTERPRISES
}

Abstract: The article revealed the specifics of risks of oilseed industry enterprises in Ukraine. It was found that development of effective risk management in the domestic oilseed enterprises slowed down by number of problems, among which are the lack of quality of human resources for risk management, the imperfection of incoming information and its processing methods, the lack of skills of work with national standards of risk management. It was revealed that the most dangerous kinds of risk in the current conditions are market, financial (credit, operational, currency, investment), customs and legal risks.

Key words: risk management, risk reduction, the methods of risk management, security, oilseed industry.

Language: Russian

Citation: Posokhov IM, Zhadan UV (2017) THE FEATURES OF RISK MANAGEMENT ON OILSEED INDUSTRY ENTERPRISES. ISJ Theoretical \& Applied Science, 01 (45): 101-108.

Soi: http://s-o-i.org/1.1/TAS-01-45-19 Doi: crossef https://dx.doi.org/10.15863/TAS.2017.01.45.19

\section{ОСОБЕННОСТИ УПРАВЛЕНИЯ РИСКАМИ НА ПРЕДПРИЯТИЯХ МАСЛОЖИРОВОЙ ОТРАСЛИ}

Аннотация: В статье выявлена специфика рисков предприятий масложсировой отрасли Украины. Установлено, что развитие эффективного риск-менеджмента на отечественных масложировых предприятиях тормозится рядом проблем, среди которых можно выделить недостаточный уровень квалификации менеджеров и персонала по управлению рисками, несовершенство входящей информации и методов ее обработки, отсутствие навыков работы со стандартами по управлению рисками. Выявлено, что наиболее опасными рисками в сложившихся условиях являются рыночные, финансовые (кредитные, операционные, валютные, инвестиционные), таможенные и юридчческие риски.

Ключевые слова: риск-менеджмент, снижение риска, методы управления риском, безопасность, масложировая отрасль.

\section{Постановка проблемы.}

Масложировая отрасль играет очень важную роль в экономике Украины. В этом секторе функционирует ряд крупнейших и наиболее прибыльных предприятий Украины.

Выручка от экспорта продукции масложировых предприятий является одним из источников валютных поступлений в экономику и Украины. При этом управление рисками на предприятиях отрасли имеет характерные особенности, которые недостаточно исследованы в научных публикациях, что обуславливает актуальность темы статьи.

На современном этапе развития, в условиях продолжающегося кризиса, экономика Украины и в частности, для агропромышленный комплекс, частью которого является масложировая промышленность функционируют в сложных экономических условиях.

Нестабильность кредитно-финансовой системы страны в большой степени отражается на аграрной сфере, в том числе и на масложировом комплексе, в частности, способствуя формированию рисков, связанных с покупательной способностью денег (инфляционных рисков),

кредитных, рыночных, инвестиционных операци-онных рисков, рисков ликвидности.

Вместе с тем наличие разнообразных опасных факторов риска несколько компенсируется высоким уровнем прибыльности производства масла, что обусловлено, в частности, достаточно стабильным, даже в условиях кризиса, спросом на продукцию 
масложировых предприятий на внутреннем рынке и наличием значительного экспортного потенциала, который имеет резервы роста благодаря продолжающейся интеграции Украины в европейское и мировое экономическое сообщество.

Осуществление управленческого влияния на риск предполагает снижение его уровня и контроль рисков, то есть увеличение прибыльности и эффективности результатов деятельности предприятий масложировой отрасли. Таким образом, вышеизложенная информация, обусловливает научную и практическую значимость выбранного направления исследования.

\section{Анализ последних исследований и публикаций. \\ Исследованию рисков в деятельности} хозяйствующих субъектов посвятили свои работы многие ученые, в частности: А. П. Альгин, А. А. Балабай, А. Ф. Иляш, Ю. В. Калюжная, Дж. М. Кейнс, А. Маршал, К. В. Мельникова, А. Моргенштейн, Ф. Найт, Дж. Нейман, Г. Г. Пивняк, И.М. Посохов, Б. А. Райзберг, К. И. Тарасова, О. В. Тесак и многие другие.

Исследованию отдельных видов рисков в деятельности предприятий пищевой промышленности посвящены работы Т. А. Береговой, Л. А. Бывшевой, И. Г. Власенко, М. А. Волкова, Ю. Ф. Гудзь, А. А. Левицкой, О. В . Лясковского, А. М. Мьякшило, С. В. Ноженко, И. А. Плющик, Н. С. Скопенко, В. В. Ткач, А. В. Харкянен, А. А. Чигринец.

В наше время существует недостаточное количество научных исследований и публикаций, посвященных рискам на предприятиях именно масложировой отрасли.

Стоит отметить наличие диссертационного исследования А. С. Дубровой «Формирование комплексной системы управления хозяйственными рисками», выполненного по материалам предприятий масложировой отрасли Украины в 2004 г. и научные статьи этого же автора.

А. С. Дубровой исследовано влияние отраслевого риска на деятельность масложировых предприятий и определены особенности их функционирования в условиях неопределенности; осуществлена аналитическая оценка предпринимательских рисков и определена специфика действующей системы риск-менеджмента; обоснованы направления и особенности формирования комплексной системы управления хозяйственными рисками масложировых предприятий; углублены теоретико-методические основы анализа рисков предпринимательской деятельности; определены концептуальные основы управления рисками на предприятиях; разработаны теоретические и практические рекомендации по оптимизации модели риск-менеджмента.

Выделение нерешенных ранее частей общей проблемы. В настоящее время остаются не исследованными проблемы, препятствующие строительству и развитию эффективного рискменеджмента на отечественных предприятиях масложировой отрасли Украины, определение наиболее опасных видов рисков для масложировой отрасли Украины в современных условиях неопределенности, специфика рисков предприятий масложировой отрасли Украины. Это обуславливает актуальность выбранной тематики для дальнейших научных исследований.

Формулировка целей статьи. Целью статьи является анализ особенностей управления рисками на предприятиях масложировой отрасли.

Изложение основного материала. В условиях рыночной экономики деятельность любого хозяйствующего субъекта, осуществляюего предпринимательскую деятельность, независимо от формы собственности и сферы деятельности, подвержена влиянию множества факторов риска, как внутренних, проявляющиеся в процессе управления предприятием, так и внешних, обусловленных влиянием внешней среды на функционирование предприятия.

Подвержены этому влиянию и предприятия масложировой отрасли Украины, которые в течение последних лет динамично развиваются. Например, объемы производства масличных культур за последние 15 лет выросли более чем в 7 раз, при этом производство семян подсолнечника увеличилось в 5,7 раза - с 2,25 млн. т. в 2001/2002 маркетинговом году до 12,9 млн. т. в 2016 / 2017 маркетинговом году. Объемы производства и экспорта подсолнечного масла выросли в 5,7 и 11 раз соответственно. Так, если в сезоне 2001/2002 маркетингового года производство подсолнечного масла составило 0,85 млн. т., то, по прогнозам аналитиков, в 2016/2017 маркетинговом году этот показатель составит 5,28 млн. т. Экспорт подсолнечного масла в сезоне 2001/2002 г.. составил 0,42 млн. т., а в сезоне 2016/2017 г.. аналитики прогнозируют рост экспорта до 4,75 млн. т. [1].

При этом география экспорта украинского подсолнечного масла расширилась с более 30 стран в 2001/2002 маркетинговом году до более чем 100 стран мира в сезоне 2015/2016 г. Пятерку крупнейших импортеров украинского подсолнечного масла составляют: Индия, Китай, Испания, Нидерланды, Италия [1].

Но, несмотря на динамичное развитие, последние годы для предприятий масложировой 
отрасли не были простыми. Кризис 2008-2009 гг., который трансформировался в стагнацию 20112013 гг. и глубочайший кризис 2014-2016 гг., который наступил впоследствии в Украине, актуализировали проблемы эффективного управления рисками на предприятиях масложировой отрасли.

В настоящее время владельцы украинских масложировых предприятий все больше понимают необходимость упорядочения процессов управления рисками, их своевременного выявления, прогнозирования и предотвращения возникновения нежелательных для предприятия последствий.

Однако создание и развитие эффективного риск-менеджмента на отечественных масложировых предприятиях тормозится рядом проблем, среди которых можно выделить недостаточный уровень квалификации менеджеров и персонала по управлению рисками, несовершенство входной информации и методов ее обработки, отсутствие навыков работы со стандартами по управлению рисками [2].

Наиболее опасными рисками в сложившихся условиях, являются природно-климатические, рыночные, финансовые (кредитные, операционные, валютные, инвестиционные), таможенные и юридические риски. Природноклиматические риски в стране возникают из-за неблагоприятных природно-климатические условий, что снижает урожайность масличных культур и приводит к удорожанию сырья для производителей. Рыночные риски для предприятия проявляются в увеличении выпуска конкурентами аналогичной продукции или продукции лучшего качества, выходе на рынок новых производителей, применении ими агрессивной маркетинговой и ценовой политики. Они также могут реализоваться из-за уменьшения спроса на продукцию предприятия на внутреннем или внешнем рынках. Финансовые риски в отечественных условиях проявляются настолько часто, что уже начинают восприниматься как действительность. Цена на кредитные ресурсы и до 2008 г. была намного выше среднемировых показателей, а в течение последних 8 лет она приводит к нерентабельности использования этого вида финансирования для большинства предприятий отрасли. То же касается и валютных рисков, и это прекрасно демонстрирует динамика валютных курсов в Украине (уменьшение курса гривны к мировым валютам в более 5 раз с 2008 г. по 2016 г.). Низкий курс гривны препятствует привлечению иностранных инвестиций в отрасль, однако предоставляет дополнительные преимущества производителям, экспортирующим подсолнечное масло за границу. Таможенные риски для предприятий масложировой отрасли заключаются в возможном непредсказуемом увеличении таможенных платежей и применении ограничений (например, квот), что оказывает отрицательное влияние на прибыльность и ритмичность выполнения экспортно-импортных контрактов. Юридические риски могут иметь различную природу, в частности это изменения в законодательстве, нарушение авторских прав на торговые марки, недостаточная юридическая защищенность ведения бизнеса в Украине, коррумпированность судебной системы и другие.

В качестве сопутствующих негативных факторов для масложировых предприятий следует отметить высокую конкуренцию в отрасли и значительную волатильность цен на сырье и продукцию как на внутреннем, так и на внешнем рынках, стремительный рост цен на оборудование, материалы, тару, тепловую и электрическую энергию, транспортные услуги, колебания курсов валют и т. п.

Общими характерными чертами большинства масложировых предприятий являются: непре-рывность технологического процесса, обусловлен-ная необходимостью ритмичной переработки сырья; тесная связь между отдельными составляющими технологического процесса; четкое разбиение процесса по стадиям; ограниченный срок годности сырья и готовой продукции; зависимость производства от урожая масличных культур и уровня спроса на готовую продукцию мировом рынке.

В связи с указанными особенностями от отдела маркетинга требуется слаженное и быстрое согласование действий по приему заявок, производства масложировой продукции и отгрузки ее потребителям.

От выстраивания надежных отношений с поставщиками и другими видами контрагентов, предоставляющих услуги предприятию, зависит эффективность всей деятельности предприятия. Роль отдела маркетинга во взаимодействии с отделом риск-менеджмента в процессе управления контрактами с поставщиками и закупками заключается в оценке полного, своевременного обеспечения потребностей предприятия в закупке сырья, материалов, оборудования, работ и услуг требуемого качества и по оптимальной цене, а также в осуществлении контроля конкурентоспособности цен на выпускаемую продукцию предприятия. В работе c поставщиками отдел маркетинга во взаимодействии с отделом риск-менеджмента масложирового предприятия должны проводить тщательный анализ действующих контрагентов, изучать альтернативные коммерческие предложения, контролировать выполнение существующих задач в соответствии с условиями договоров.

Указанный этап работ на предприятиях

ISPC Perspectives in science for 2017, 
масложировой отрасли характеризуется высокой степенью рисков, связанных со злоупотреблениями сотрудников предприятия. Наиболее распростра-ненными примерами таких злоупотреблений в производственной практике предприятий отрасли являются: организация фиктивных сделок, завышение цен на поставку продукции, получение непреднамеренной выгоды за улучшение условий поставки, закупка неликвидных запасов. Встроенная в систему управления предприятием система рискменеджмента, формирует внутренний контроль предприятия, позволяет вовремя идентифицировать данные риски и принимать превентивные меры по их устранению.

Следующим сложным этапом работы предприятий масложировой промышленности является доставка готовой продукции потребителям. Доставка осуществляется либо собственным автотранспортом или транспортом, принадлежащим сторонним организациям. В этой ситуации возникает необходимость оперативно отслеживать выполнение графика, контролировать процесс отгрузки и вести точный учет времени и стоимости работы автотранспортных средств.

Для предприятий масложировой отрасли характерно большое количество контрагентов. Подразделение службы сбыта ежедневно обрабатывает заявки, количество которых может достигать нескольких сотен. Ряду контрагентов, прежде всего - большим торговым сетям, масло поставляется под их собственными брендами, в емкостях различных объемов и форм, что затрудняет процессы производства, хранения и отгрузки готовой продукции. Поэтому непременным требованием к системе управления рисками является возможность индивидуальной работы и сбора информации о каждом контрагенте и быстрой реорганизации системы снабжения и сбыта в соответствии с требованиями рынка.

Наличие большого количества контрагентов влечет за собой также разнообразие форм расчетов с ними и, соответственно, затрудняет контроль выполнения обязательств и платежей. Задача оперативного отслеживания взаиморасчетов с поставщиками и покупателями - непременное условие выполнения бюджета такого предприятия. Очевидно, что без хорошо отработанной модели этого процесса возникает риск повышения объемов дебиторской задолженности, и, как следствие, нехватка оборотных средств, что отрицательно сказывается на деятельности масложирового предприятия. В целом, для предприятий масложировой отрасли крайне важна полная функциональность системы в сфере моделирования производства и поддержание в ней как процессного, так и дискретного производства в рамках единого согласованного решения и контро-ля всех возможных рисков. Разработка инструмен-тов управления рисками для предприятий масложировой промышленности - актуальное решение. Система управления рисками не может быть односторонней, она должна быть связана с одной стороны, с технологией производства, а с другой - исключать дублирование работ и искаже-ние информации. Поэтому одной из основных задач системы управления рисками на таком предприятии является учет всех факторов риска на всех стадиях производственного цикла, начиная от выбора поставщиков сырья и заканчивая выбором каналов распределения готовой продукции.

Совершенствование управления рисками на предприятия масложировой отрасли предусматри-вает создание соответствующего организационного обеспечения, наличие методического и информаци-онного обеспечения, а также квалифицированного персонала, обладающего специальными знаниями и навыками по управлению рисками.

В целях повышения эффективности управления рисками на масложировом предприятии предложено провести определенные реорганизационные мероприятия.

Во-первых, оправданным будет создание службы экономической и информационной безопасности, которая административно будет подчиняться директору по безопасности, а функционально - директору по экономике и финансам. Основными функциями этой службы будут: определение перечня информации со статусом коммерческой тайны, а также перечня лиц, которые несут ответственность за ее сохранность; защита информации на предприятия; установка определенных регламентов и правил информационной безопасности; контроль и проверка всех подразделений предприятия по выполнению этих правил.

Во-вторых, целесообразно сформировать в организационной структуре специальное подразделение - отдел управления рисками, возглавляемый руководителем отдела по управлению рисками, который будет заниматься исключительно проблемами управления рисками и координировать деятельность всех подразделений по сбору и анализу информации с целью регулирования рисковых событий и обеспечения компенсации возможных потерь и убытков. Отдел управления рисками должен подчиняться директору по экономике и финансам, собирать и анализировать информацию из всех подразделений и служб предприятия. 
Функции руководителя подразделения по управлению рисками на предприятии масложировой отрасли могут быть достаточно широкие. В его ведении должны находиться вопросы обеспечения безопасности и контроля рисков. Он будет формировать организационную структуру отдела и системы управления риском на предприятии и разрабатывать основные положения и инструкции, связанные с этой деятельностью.

С целью формирования более эффективной организационной структуры управления рисками на предприятии целесообразно введение элементов матричной организационной структуры, которая представляет собой сложную структуру, ориентированную на инновации, предъявляет особые требования к персоналу и уровню координации различных работ на предприятии. Такой подход особенно эффективен и необходим в условиях динамичного изменения внешней среды.

Основной задачей руководителя отдела управления рисками и его подразделения должна являться разработка стратегии и принципов управления риском на предприятии, изложенных во внутренних нормативных документах, основным из которых является «Положение по управлению рисками». Основными функции отдела по управле-нию рисками на предприятии масложировой промышленности служат: выявление риска; сбор, анализ и статистическая обработка информации; реализация мероприятий по повышению уровня безопасности предприятия; разработка превентив-ных и корректирующих действий; разработка альтернативных вариантов принятия решений; предоставление информации о возможных рисках руководству; мониторинг и контроль уровня риска на предприятии; реализация программ по повышению квалификации персонала.

В-третьих, для получения синергетического эффекта от реализации процессов управления рисками необходимо совершенствовать взаимодей-ствие между подразделениями предприятия. Для этого в каждом подразделении предприятия необходимо определить сотрудника, отвечающего за сбор и анализ информации для отдела управления рисками и прописать эти функции в его должностных инструкциях. Функционально он будет подчиняться начальнику отдела по управлению рисками, а административно непосредственно начальнику подразделения, в котором работает.

Также следует отметить, что наличие квалифицированных трудовых ресурсов необходимый элемент для эффективной работы и взаимодействия подразделений. В отделах по управлению рисками должны работать специально подготовленные специалисты, имеющие профессиональные компетентности по управлению рисками и опыт работы в масложировой отрасли. Их навыки должны совершенствоваться, а уровень квалификации постоянно повышаться.

Совершенствуя организационную структуру предприятия и научив сотрудников выявлять угрозы и контролировать развитие нежелательных событий, можно будет разработать эффективную программу оценки и управления рисками.

Оценка риска - это определение количествен-ным или качественным способом величины (степени) риска. Оценка риска направлена на то, чтобы количественно выразить риски, провести их анализ и сравнение.

Главная задача анализа состоит в выявлении и идентификации всех возможных видов рисков. Необходимым условием при этом является наличие ранжирования и систематизации рисков, влияющих на деятельность организации. Качественный анализ рисков является основой для дальнейшего количественного анализа риска. Количественный анализ рисков предполагает: численное определе-ние размеров отдельных рисков и риск-решения в целом; выделение группы рисков, с которыми придется столкнуться предприятию; выделение наиболее вероятных по возникновению и весомых по величине потерь, вследствие проявления рисков, которые станут объектом дальнейшего анализа для принятия решения о целесообразности реализации проекта в том или ином виде.

В научных исследованиях, посвященных проблемам риска [3, 4], выделено несколько групп методов, позволяющих провести количественную оценку риска: статистические методы (однофактор-ные, многофакторные) расчетно-аналитические методы (анализ чувствительности, проверка устойчивости и определение предельных значений параметров, определение точки безубыточности; корректировки параметров; построение дерева решений, анализ сценариев, метод Монте-Карло); экспертные методы.

Специалисты выделяют пять основных мето-дов управления риском - уклонение, локализацию, диверсификацию, компенсацию, передачу $[3 ; 5 ; 6 ; 7 ; 10]$.

Выбор методов управления рисками должен быть продуманным и эффективным. Управление рисками - управленческая деятельность, направленная на идентификацию, классификацию, анализ и оценку, планирование, прогнозирование рисков, разработку мер по предотвращению или снижению отрицательных последствий риска.

Уклонение от риска состоит в том, что не следует совершать операции, связанные с существенными рисками для организации [8]. На 
первый взгляд, этот метод кажется предельно простым. Однако для эффективного применения данного метода необходимо иметь в штате организации сотрудников, способных дать предварительную оценку уровня риска операции, оценить ожидаемые выгоды, потенциальные убытки и их последствия для предприятия и принять квалифицированное решение о проведении или отказе от проведения соответствующей операции. Успешное осуществление данной процедуры во многом зависит от статистической информации о тех негативных явлениях, которые возникали в деятельности предприятия в прошлом. Таким образом, применение данного метода может быть рекомендовано предприятиям, работающим на рынке длительное время, способным оценить свой предыдущий опыт и принять на его основе эффективное решение для своего развития.

Существуют следующие методы уклонения от риска [9]:

1) дублирование участков предприятия, нахо-дящихся под риском, что повышает их надежность;

2) сокращение времени пребывания в опасных зонах, предполагает, в частности, изменение марш-рутов и технологий, установление ограничений, контроль доступа, ускорение сделок и т. п.;

3) предоставление информации статуса коммерческой тайны;

4) введение специального ограничения делопроизводства;

5) мониторинг информации, который включает проектирование и формирование необходимых потоков информации, наблюдение и управление фактическим потоками информации;

6) отказ от сотрудничества с ненадежными контрагентами;

7) отказ от реализации рискованных проектов;

8) поиск гарантов, поручителей при заключении высокорисковых сделок, контрактов.

Локализация рисков или лимитирование используется в случаях, когда удается достаточно четко идентифицировать риски и источники их возникновения. Реализация происходит путем установления внутренних ограничительных нормативов и проведения ряда комплексных мер, направленных на разграничение полномочий, как между отдельными должностными лицами, так и между структурными подразделениями организации и органами ее управления. В рамках данного метода, важен периодический пересмотр уровня установленных лимитов в связи с изменчивостью рисков во времени таким образом, чтобы это не выходило за пределы существующих лимитов и не привело к возникновению убытков для предприятия. Внедрение данного метода рискменеджмента является одним из самых распространенных на практике, так как его осуществление не требует высоких затрат.

Принцип диверсификации, основанный на разделении рисков, препятствует их концентрации [10]. Как правило, диверсификация является способом снижения несистематического риска, обеспечивает эффект нейтрализации отдельных рисков, часто носит ограниченный характер. На предприятиях масложировой отрасли она может применяться для оптимизации бизнес-процессов, отдельных направлений деятельности, обеспечения баланса структуры активов и капитала и т. п.

Метод компенсации рисков характеризуется опережающим воздействием на возможные негативные последствия событий. Предупреждение угроз осуществляется за счет применения комплексной защиты на предприятии путем внедрения внутренней структуры планирования, прогнозирования и мониторинга. Полученные на основе этого аналитические данные помогают установить тенденции развития предприятия, его потенциальные возможности, выявить сильные и слабые стороны, скорректировать стратегические планы, а главное выиграть время для принятия конструктивных управленческих решений.

Передача рисков заключается в переносе риска на любое третье лицо или другие лица. Самым известным способом является страхование. Несмотря на безусловные преимущества данного метода, его использование не всегда целесообразно для отечественных предприятий. Во-первых, стра-хование всех видов риска предприятия является достаточно дорогим методом, что значительно снижает его привлекательность и сужает круг возможного применения для защиты от рисков предприятия, которые характеризуются существен-ными и даже катастрофическими убытками, но относительно низкой вероятностью их возникновения.

Во-вторых, в отечественных условиях любой риск, на подлежит страхованию, трансформирует-ся в кредитный, так как существует значительный риск неплатежа со стороны страховщика.

Другим способом передачи рисков является перенос риска на бизнес партнера путем заключения договора факторинга, форфейтинга, поручительства и т. д.

В целом управление рисками на масложировых предприятиях должно иметь четко выстроенную стратегию, тактику и методы реализации, с возможностью вносить в них быстрые, оперативные изменения. 
Выводы и перспективы дальнейших исследований. Управление рисками является неотъемлемой частью в общей системе принятия управленческих решений на предприятиях масложировой отрасли. Осуществление управленческого влияния на риск предполагает снижение его уровня. Полностью исключить риск невозможно, поскольку первоначальный риск может трансформироваться в другие риски.

На наш взгляд, встроенная в управленческий процесс предприятия политика управления рисками должна способствовать выявлению, управлению и контролю событий, которые могут негативно влиять на эффективное развитие предприятия.

Цели и задачи системы управления рисками должны быть согласованы с общей стратегией развития предприятия, а способы снижения риска - адекватны по отношению к принципам организации и ведения бизнеса на предприятиях отрасли.
Установлено, что развитие эффективного риск-менеджмента на отечественных масложировых предприятиях тормозится рядом проблем, среди которых можно выделить недостаточный уровень квалификации менеджеров и персонала по управлению рисками, несовершенство входящей информации и методов ее обработки, отсутствие навыков работы со стандартами по управлению рисками.

Выявлено, что наиболее опасными рисками в сложившихся условиях являются рыночные, финансовые (кредитные, операционные, валютные, инвестиционные), таможенные и юридические риски.

Перспективами дальнейших исследований является исследование вероятностных методов оценки рисков с целью повышения эффективности управления на отечественных предприятиях масложировой отрасли.

\section{References:}

1. (2016) Maslozhy`rova promy`slovist` Materialy` konferenciyi 26-27 zhovtnya 2016 r. $\mathrm{v}$ m. Odesa [Fat and oil industry. Materials of the conference, October, 26-27, in Odessa]. Available:

inform.com/ru/conferences/fat-and-oil2016/about (Accessed: 10.01.2017).

2. (2015) DSTU IEC/ISO 31010:2013 Keruvannya ry`zy`kom. Metody`zagal`nogo ocinyuvannya ry`zy`ku (IEC/ISO 31010:2009, IDT). [Managing risk. The methods of general risk assessment (IEC/ISO 31010:2009, IDT]. Chy`nny`j vid01.07.2014. Kyiv, Minekonomrozvy`tku Ukrayiny`[Active from 01.07.2014. Kyiv: Ministry of Economic Development of Ukraine], 73.

3. Posokhov IM (2013) Doslidzhennya metodiv ocinky` ry`zy`kiv korporacij [The research methods for assessing risk corporations]. Yevropejs`ky`j vektor ekonomichnogo rozvy`tku - European vector of economic development, 2, 211-217.

4. Kuz`min OY, Podol`chak NY, Matviyishy`n VY (2011) Upravlinnya ta zny`zhennya rivnya ry`zy`kiv energozabezpechennya pidpry`yemstv [Risk management and reduction level of energy supply enterprises]. Monografiya, Nacz. un-t L`viv. politexnika - L`viv: Mis`ki informacijni sy`stemy`. Monograph Nat. Univ
Lviv. Polytechnic. The city information systems, 235.

5. Zborovs`ka OM (2013) Upravlinnya ry`zy`konasy`chenistyu ekonomichnoyi diyal’nosti pidpry`yemstv [The risk management saturation of enterprises economic activity]. Zbirny`k naukovy`x pracz` Cherkas`kogo derzhavnogo texnologichnogo universy`tetu. Ser:Ekonomichni nauky Scientific works of Cherkassy State Technological University.: Economic Sciences, 33(2), 42-46.

6. Posokhov IM (2012) Suchasny`j stan metody`chnogo zabezpechennya upravlinnya ry`zy`kamy` korporacij [The current state of methodical providing of corporations risk management]. Biznes Inform - Business Inform, 10, 266-271.

7. Skopenko NS, P'yankova OV (2014) Teorety`ko-metodologichni zasady` ry`zy`kmenedzh-mentu yak instrumentu upravlinnya gospodars`ky`m ry`zy`kom pidpry`yemstva [Theoretical and methodological principles of risk management as a tool of economic management of risk enterprise]. Ekonomika i organizaciya upravlinnya - Economy i management organization,1(17) - 2(18), 238245.

8. (2017) Ideologiya ry`zy`k-menedzhmentu (n.d.). [The ideology of risk management] 


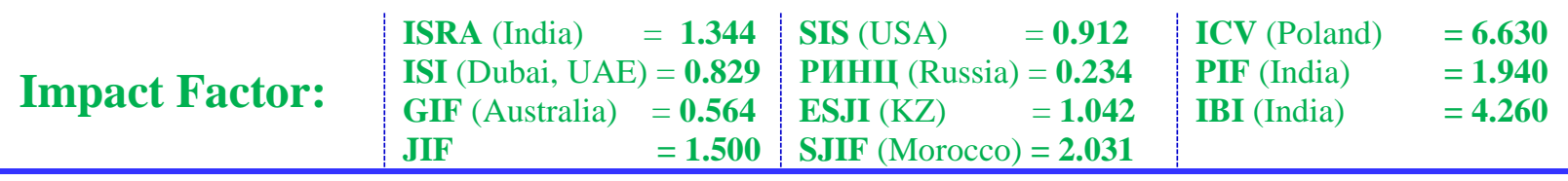

Biznes Portal Lucz ka -Lutsk Business Portal.. Available: http://toplutsk.com/articlesarticle 521.html (Accessed: 10.01.2017).

9. (2017) Prakty`chesky`j y`nstrumentary`j upravle-ny`ya ry`skamy` (n.d.). [ The practical tools of risk management] Ely`tary`um Elitarium. http://www.elitarium.ru/instrumentariji_upravle nija riskami/ (Accessed: 10.01.2017).

10. Posokhov I.M. (2014) Teoretychni ta praktychni aspekty upravlinnya ryzykamy korporatsiy : monohrafiya / I. M. Posokhov. Kharkiv : PVPP "SLOVO", 2014, 499. 